NBER WORKING PAPER SERIES

\title{
DOES ANTICIPATED MONETARY POLICY MATTER? \\ AN ECONOMETRIC INVESTIGATION
}

Frederic S. Mishkin

Working Paper No. 506

NATIONAL BUREAU OF ECONOMIC RESEARCH

1050 Massachusetts Avenue

Cambridge MA 02138

July 1980

I would like to thank the following for their helpful comments: Andrew Abel, Robert Flood, Peter Garber, Nathaniel Gregory, Robert Lucas, Bennett McCallum, Kenneth Singleton and the participants in the Money Workshops at the University of Chicago and the University of Virginia. This research has been supported by the National Science Foundation. The research reported here is part of the INBER's research program in Economic Fluctuations. Any opinions expressed are those of the author and not those of the National Bureau of Economic Research. 
Does Anticipated Monetary Policy Matter?

\section{$\underline{\text { ABSTRACT }}$}

Recent theorizing with business cycle models which incorporate features of the Friedman-Phelps natural rate model along with rational expectations lead to the following policy conclusions. Anticipated changes in aggregate demand policy will have already been taken into account in economic agents behavior and will thus envoke no further output or employment response. Therefore, deterministic feedback policy rules will have no impact on output fluctuations in the economy. These policy implications of what Modigliani has dubbed the Macro Rational Expectations (MRE) hypothesis are of such importance that a wide range of empirical research is needed for its verification or refutation.

Recent empirical work has tested the "neutrality" implication of the MRE hypothesis that an icipated monetary policy does not affect output or unemployment. Although this empirical work has frequently been favorable to the MRE hypothesis, it suffers from several deficiencies that create suspicion about the robustness of the results. This paper is an attempt to conduct an econometric investigation of the implications of the MRE hypothesis which does not suffer from these deficiencies. The results here strongly reject the neutrality implications of the MRE hypothesis: unanticipated movements in monetary policy are not found to have a larger impact on output and unemployment than anticipated movements. This evidence casts doubt on previous evidence that is cited as supporting the view that only unanticipated monetary policy is relevant to the business cycle.

Frederic Mishkin Department of Economics University of Chicago 1126 East 59th Street Chicago, Illinois 60637 
INTRODUCTION

Recent theorizing has focused on business cycle models which incorporate features of the natural rate model of Friedman(1968) and Phelps (1970) with the assumption that expectations are rational in the sense of Muth (1961). An 1mportant conclusion from this research [Lucas (1972), Sargent and Wallace (1975) and Barro (1976)] is that ant1clpated changes in aggregate demand pollcy w1ll have already been taken Into account in economic agents' behavior and will thus evoke no further output or employment response. Therefore, determinlstic, feedback, policy rules will have no impact on output fluctuations in the economy. This leads to the implied policy prescription that the monetary authorIties should pursue a price level stabilization target, and a constant money growth rule is one candidate for such a pollcy ( $e_{\circ} g_{0}$, Wallace (1976)). These policy Implications of what Modiglianl (1977) has dubbed the Macro Rational Expectations (MRE) hypothesis runs counter to much previous macroeconomic theorizing (as well as the views in policy making circles), It is thus of such importance that a wide range of empirical research is needed for its verification or refutation. Recent empirical work (Barro (1977, 1979), Barro and Rush (1978), Grossman (1979),..Leideman (1978) and Small (1978)) has tested the "neutrality" implication of the MRE hypothesis that anticipated monetary policy does not matter: or to be more precise, that deviations of both output and unemployment from their natural levels should be correlated with only unanticipated changes in monetary polfcy. Although this 
empirical work has frequently been favorable to the MRE hypothesis, as will be shown below, it does suffer from several deficiencies that create suspicion about the robustness of the results. There is thus a need for further emirical research which does not suffer from these deficiencies, and this has stimulated this paper's attempt to provide additional econometric evidence on this issue.

The next section of the paper discusses the previous empirical research on this subject, and the econometric methodology in the empirical tests of this paper. The following section then presents the outcome from these empirical tests and a final section contains concluding remarks. 
II

A DISCUSSION OF THE METHODOLOGY

The tests discussed here are based on a model of the form:

(1) $y_{t}=y_{t}^{*}+\sum \beta_{i}\left(M_{t-1}-M_{t-1}^{e}\right)+\varepsilon_{t}$ $i=0$

where

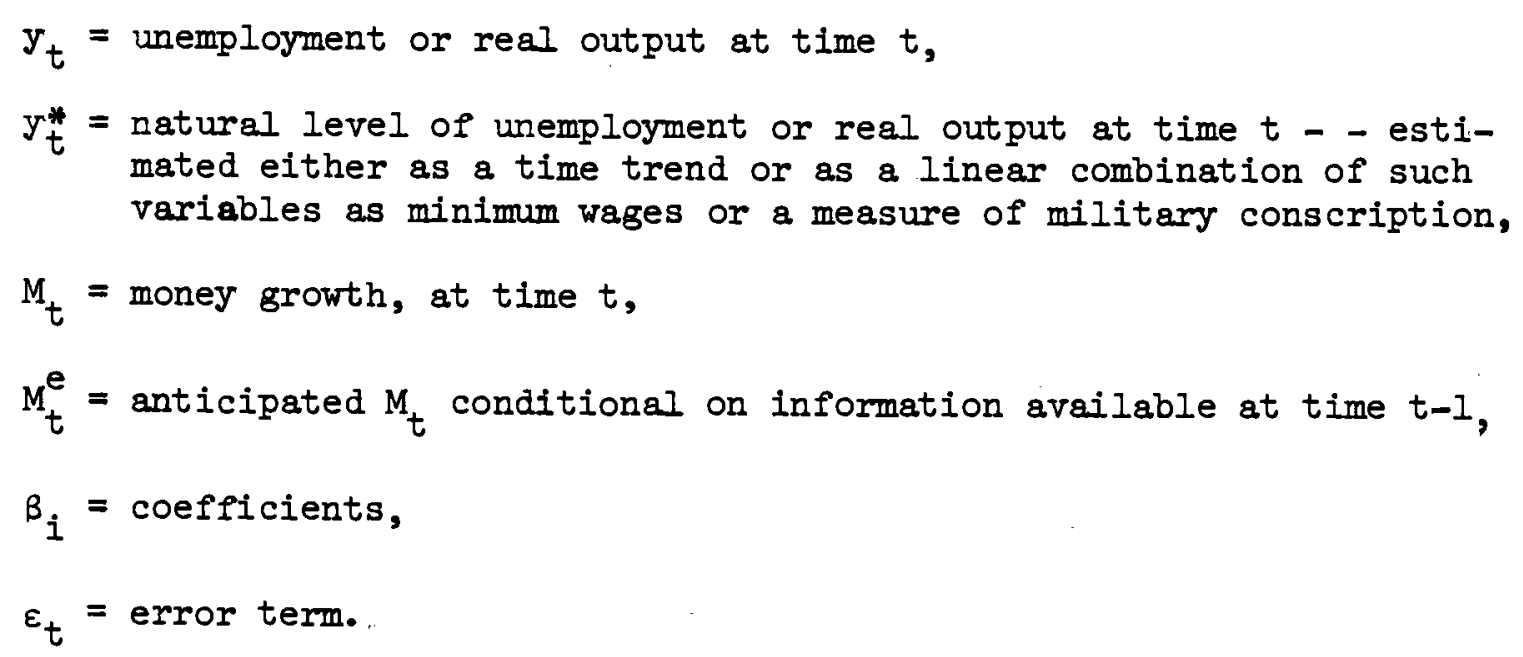
mated either as a time trend or as a linear combination of such variables as minimum wages or a measure of military conscription,

The first thing to note about this equation is that the $\beta$ coefficients are not identified unless we impose some assumption on the correlation of the error term, $\varepsilon$, and the right-hand-side variables. $I$ If ( $I$ ) is not a true reduced form because current or lagged $M-M^{e}$ are correlated with the error term, then estimates of the $\beta^{\prime}$ 's will not be consistent using usual least squares estimation methods.

IThis is easily seen in a case rorked out by Abel and Mishkin (1979) where only the contemporaneous unanticipated variable is included in an equation like ( 1 ). 
The implicit assumption made in all the empirical work cited in the Introduction holds that all the right-hand-side variables are exogenous and hence are uncorrelated with the error term. However this assumption is never subjected to tests in this work and so we must be careful in interpreting the evidence on the $\beta^{\prime} s$.

Rational expectations implies that the anticipations of $M_{t}$ will be formed optimally, using all available information, and as is usual in this literature, models are assumed to be linear. An equation which can be used to generate optimal, linear forecasts is thus

(2) $M_{t}=z_{t} \gamma+u_{t}$

where $z_{t}=$ a vector of variables available at time $t-1$,

$$
\gamma=\text { a vector of coefficients, }
$$

$u_{t}=$ error term which is assumed to be uncorrelated with any information available at $t-l$ (which includes $z_{t}$ or $u_{t-i}$ for all $i \geq 1$ and hence $u_{t}$ is white noise).

An optimal forecast for $M_{t}$ thén simply involves taking expectations of equation (2) conditional on information available at $t-l$.

Hence:

(3) $M_{t}^{e}=z_{t} \gamma$

and substituting into equation (1) we have:

(4) $y_{t}=y_{t}^{*}+\sum_{i=0}^{N} \beta_{i}\left(M_{t-i}-z_{t-i} \gamma\right)+\varepsilon_{t}$ 
ESTIMATION ISSUES

There are two methods that have been used to estimate the equation (4) model. Barro (1977) uses a two-step precedure where the money growth equation (2) is estimated by ordinary least squares (OLS) over the sample period, and the residuals from this regression are then used as the unanticipated movements in money growth: i.e., $\gamma$ in (4) is assumed to equal the OLS estimate of $\gamma$ in (2). Tests of the neutrality proposition then involve adding current and lagged actual money growth variables to equation (4) and testing with OIS the null hypothesis that their coefficients are equal to zero.

There are several problems with this methodology. Most important is the econometric criticism of this appraoch. As Durbin (1970) and Sims (1977) have shown, using residuals from one regression as variables in another regression, as occurs in the above approach, is econometrically dangerous and has often led to misleading results. ${ }^{2}$ The specific problem with this twostep procedure is not that the parameter estimates will be inconsistent, but is rather that the resulting test statistics are inappropriate. This procedure implicitly assumes that the covarlance of the $\beta$ and $\gamma$ estimates are zero. When there are off-diagonal elements in the information matrix of the joint estimates, as here, then ignoring them as is done in the two step procedure will lead to test statistics that do not have the correct asymptotic distribution. Misleading inference is then a possible outcome of using this two-step methodology.

In addition, this methodology does not allow a full testing of the implications of the MRE hypothesis. This hypothesis embodies two propositions: 1) that expectations are rational and 2) that anticipated aggregate demand 
policy, in this case monetary policy, does not matter. The two step procedure is only capable of testing for the second proposition of neutrality under the maintained hypothesis of rational expectations. It cannot test for the rationality of expectations directly.

The second method for estimating the equation (4) model involves joint, non-linear estimation of the equations (2) and (4) system, imposing the constraints that the $\gamma$ are equal in (2) and (4). This procedure is superior to the two-step procedure although it is far more expensive to compute. Not only will more efficient parameter estimates of $\beta^{\prime} s$ and $\gamma$ result because both (2) and (4) make use of information from each other in the estimation process, but the tests will be more efficient as well. In addition, this non-linear procedure generates valid tests of both implications of the MRE hypothesis.

A joint test of both the neutrality and rational expectations propositions involves the following. If the constraints due to the neutrality proposition were relaxed, then output and unemployment deviations from their natural levels could also be correlated with the anticipated movements in monetary policy. The resulting model would be:

$$
y_{t}=y_{t}^{*}+\sum_{i=0}^{N} \beta_{i}\left(M_{t-i}-M_{t-1}^{e}\right)+\sum_{i=0}^{N} \delta_{i} M_{t-i}^{e}+\varepsilon_{t}
$$

and imposing rational expectations using (2) in order to specify $M^{e}$, we have ${ }^{3}$

$$
\begin{aligned}
& { }^{3} \text { An equivalent way of constructing this test is to write (6) as } \\
& \qquad y_{t}=y_{t}^{*}+\sum_{i=0}^{N} \theta_{i}\left(M_{t-i}-z_{t-i} \gamma^{*}\right)+\sum_{i=0} \alpha_{i} M_{t-i}+\varepsilon_{t}
\end{aligned}
$$

where $\alpha_{i}=\delta_{i}$ and $\theta_{i}=\beta_{i}-\delta_{i}$. The test is then generated using this equivalent equation instead of (6). This procedure is analogous to that used by Barro (1977). 


$$
y_{t}=y_{t}^{*}+\sum_{i=0}^{N} \beta_{i}\left(M_{t-i}-z_{t-i} \gamma^{*}\right)+\sum_{i=0}^{N} \delta_{i} z_{t-i} \gamma^{*}+\varepsilon_{t}
$$

where $\gamma=\gamma^{*}$.

The joint test involves a likelihood ratio test for whether the (2) and (4) system satisfies the rationality constraints that the $\gamma$ are equal in both equations as well as the neutrallty constraints $\left(\delta_{i}=0\right)$ that exclude the anticipated M's from (4). One way to proceed is to estimate with fullinformation-maximum-likelihood (FIML) the constrained (2) and (4) system, as well as the unconstrained (2) and (6) system where $\delta_{i}=0$ and $\gamma=\gamma$ * are not imposed. Then the likelihood ratio statistic

$$
-2 \log \left(L^{c} / L^{u} L\right.
$$

is distributed asymptotically as $x^{2}(q)$ : where $q$ is the number of constraints, $I^{c}=$ likelihood of the esttmated constrained system and $I^{u}=$ the likelihood of the estimated unconstrained system. Comparison of this statistic with the critical values of $x^{2}(q)$ then tests the null hypothesis.

Leiderman (1978) and Barro and Rush (1978) use the above estimation procedures in testing their model. Their results do confirm Barro's (1977) earlier findings with the less desirable two-step methodology: there were no significant refections of the constraints at the $5 \%$ level.

The test procedures used in this paper proceed in a sightly different way than those described above. The primary reason is purely algorithmic. A substantially larger number of parameters are estimated in the non-linear models of this study than in Leiderman (1978) or Barro and Rush (1978), making it unfeasible to use their FIML estimation packages. However, non- 
linear least squares packages are available that can handle models as complex as those estimated in this paper, and one is used here. ${ }^{4}$ In addition use of non-linear least squares estimation allows a desirable degrees of freedom correction which results in more conservative likelihood ratio statistics; this would not have been possible with FIML packages. Non-linear least squares estimation of the constrained (2) and (4) system proceeds with the same identifying assymption used in the previous research on this topic that the unemployment or output equation is a true reduced form. ${ }^{5}$ This implies that the covariance of the error terms from (2) and (4) is zero. Failure to correct for heteroscedasticity both within and across the equations in the system would also result in inappropriate test statistics, and heteroscedasticity corrections can have a major impact on the conclusions derived from regression estimates. 6 Goldfeld-Quandt (1965) tests do not reveal the presense of heteroscedasticity within the (2) and (4) equations estimated here, and it is only necessary to correct for it across equations. This is done by estimating the

${ }^{4}$ I used the NLIN procedure in SAS (STATISTICAL ANALYSIS SYSTEM). It is described in Council and Hellwig (1979).

${ }^{5}$ In the case where only contemporaneous $M-M^{e}$ appears in equation (4), the imposition of this assumption, even if it is untrue, will not invalidate the test statistics on the rationality and neutrality hypotheses. See Abel and Mishkin (1979). However, it is not clear that this desirable result that the above assumption does not matter to the tests of interest here carries over to the case where lagged $M-M^{e}$ enter equation (4).

6For example, see the discussion of Shiller's (1979) results in Mishkin $(1978)$. 
variance-covariance matrix of the residuals from the first-stage estimated (2) and (4) system to be

$$
\hat{\Sigma}=\left[\begin{array}{cc}
\mathrm{SSR}_{2} & 0 \\
\mathrm{n} & \frac{\mathrm{SSR}_{4}}{\mathrm{n}}
\end{array}\right]
$$

where $\mathrm{SSR}_{2}=$ the sum of squared residuals from equation (2) and $\mathrm{SSR}_{4}=$ the sum of squared residuals from equation (4). Then the (2) and (4) system is estimated by non-linear generalized least squares (GLS) with $\hat{\Sigma}$. A new $\hat{\Sigma}$ matrix can then be estimated in the same way, and the system reestimated again with non-linear GIS. This Iterative procedure is continued until there is little change in the $\hat{\Sigma}$ matrix, resulting, approximately, in maximum likelihood estimates. 8

If the same procedure is followed for estimating the unconstrained ststem, then this generates the following likelihood ratio statistic which tests the null hypothesis:

$$
\mathrm{n} \log \left[\operatorname{det} \hat{\Sigma}^{\mathrm{c}} / \operatorname{det} \hat{\Sigma}^{\mathrm{u}}\right]
$$

8 The iterative procedure will converge to maximum likelihood estimates since this system has a Jacobian that is triangular. Thus theorems whish show that iterative three-stage-least-squares is equivalent to FIML apply to this non-linear case as well because the determinant of the Jacobian 
where

$\mathrm{n}=$ the number of observations in each equation, det $\hat{\Sigma}^{c}=$ the determinant of the final estimated $\hat{\Sigma}$ for the constrained system,

$\operatorname{det} \hat{\Sigma}^{u}=$ the determinant of the final estimated $\hat{\Sigma}$ for the unconstrained system •

Although this likelihood ratlo statistic will be distributed asymptotically as $x^{2}(q)$ where $q$ is the number of constraints, it may be misleading in a small sample like that used here. The problem is that in the maximum likelihood calculation of the $\hat{\Sigma}^{u}$ matrix no correction is made for substantial relative differences in the degrees of freedom in estimates of each unconstrained equation. 9,10 To avoid this problem, the likelihood ratio statistics reported here are constructed as follows: The constrained

equals one. High computation costs required that iterations were continued only until the estimated variance of each eauation in the system differed by less than 5 percent. Some experimentation indicated that further iterations would have only altered the likelihood ratio statistics in the text by at most a couple of percent. This would lead to only a negligible effect on the inference drawn from these statistics.

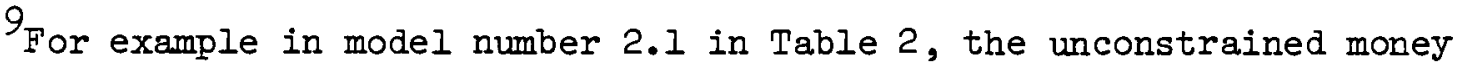
growth equation is estimated with 79 degrees of freedom, while the unconstrained output equation is estimated with only 70 degrees of freedom. This is a difference of over 10\%. In the case of Model number $5.1 \mathrm{~A}$ in Appendix 2, this problem is even more severe: the degrees of freedom for the unconstrained money growth and output equations are now 79 and 32, respectively, a difference of over $50 \%$.

${ }^{10}$ Another way of stating this problem is to say that the veighting matmatrix used for GLS, $\left(\hat{\Sigma}^{u}\right)^{-1}$, w1ll have a biased estimate of the variance of one equation relative to another. This occurs because the estimated variances are the maximum likelihood estimates (the sum of squared residuals divided by the number of observations in each equation) rather than the unbiased estimates (the sum of squared residuals divided by the degrees of freedom). 
system is estimated with the iterative procedure, and the resulting $\hat{\Sigma}^{c}$ matrix is then again used with non-linear GLS to estimate the unconstrained system. ${ }^{11}$ The likelihood ratio statistic which is also distributed asymptotically as $x^{2}(q)$ under the null hypothesis is now

$$
-2 \log \left[\frac{L^{c}\left(\hat{\Sigma}^{c}\right)}{L^{u}\left(\hat{\Sigma}^{c}\right)}\right]
$$

where the superscripts on the $\hat{\Sigma}$ indicated that the likelihoods of both the constrained and unconstrained systems were estimated with the same maximum likelihood $\hat{\Sigma}^{c}$. This likelihood ratio statistix is simply ${ }^{12}$

$$
2 n\left[\log \left(S S R^{c}\right)-\log \left(\operatorname{SSR}^{u}\right)\right]
$$

where $S_{S R}{ }^{C}=$ the sum of squared residuals from the constrained system and $S S R^{u}=$ the sum of squared residuals from the unconstrained system.

${ }^{11}$ In the constrained system where there are cross-equation constraints, the degrees of freedom does not differ across equations and $\hat{\Sigma}^{c}$ does not suffer from the degrees of freedom problem of $\hat{\Sigma}^{u}$. Thus, using $\hat{\Sigma}^{c}$ in the GLS estimate of the unconstrained system avoids the problem discussed in the text.

12 Goldfeld Quandt (1972) 
This statistic will be somewhat smaller than the alternative in (7) and hence be more conservative on rejecting the null hypothesis. ${ }^{13,14}$ To see this, realize that $L^{u}\left(\hat{\Sigma}^{c}\right) \leq I^{u}\left(\hat{\Sigma}^{u}\right)$,

implying that $-2 \log \left[\frac{I^{c}\left(\hat{\Sigma}^{c}\right)}{L^{u}\left(\hat{\Sigma}^{u}\right)}\right] \geq-2 \log \left[\frac{L^{c}\left(\hat{\Sigma}^{c}\right)}{L^{u}\left(\hat{\Sigma}^{c}\right)}\right]$.

Use of (9) rather than (7) will thus give more credibility to rejections if they occur.

If the joint hypothesis of rationality and neutrality were rejected, we would want to ask whether this rejection were due to expectations not being rational or rather the fact that anticipated policy matters? Fortunately we can obtain more information on how much the rationality versus the neutrality constraints contribute to this rejection. ${ }^{15}$ This is a particularily relevant issue because recent research [Fischer (1977) and

$13_{\text {For }}$ the models reported in the text, the likelihood ratio statistics are not appreciably different when they are calculated using (7) rather than (9). For example, in the 2.1 model the likelihood ratio statistic for the joint hypothesis calculated frmm (7) is $22.8 \mathrm{I}$ versus the value 22.69 reported in Table 3. In the models found in Appendix II which use up more degrees of freedom, the difference between the statistics calculated from ( 7 ) rather than (9) is more appreciable: for example in model 5. IA the likelihood ratio statistic for the joint hypothesis calculated from (7) is 76.33 versus the value 66.90 reported in Table $6 \mathrm{~A}$.

$14 \mathrm{My}$ discussion of the estimation techniques used in Mishkin (1980 a, b) was not as detailed as that above. However, note that the procedures used in estimation and calculation of the likelihood ratio statistics in those papers are the same as here.

${ }^{15}$ Leiderman (1978) also conducts tests of this type. 
Phelps and Taylor (1977)] has developed models in which expectations are rational and yet the nature of wage contracts result in non-neutrality. Constructing a likelihood ratio test for the neutrality constraints alone under the maintained hypothesis of rational expectations just proceeds as above, where the rationality cross-equation conatraints are imposed and the constrained system is (2) and (4), while the unconstrained system is (2) and (6) with $\gamma=\gamma^{*}$ imposed. A separate test for rational expectations (without maintaining the hypothesis of neutrality) proceeds similarly, where the constrained system is (2) and (6) imposing the rationality constraints, $\gamma=\gamma^{*}$, and the unconstrained system is (2) and (6) with the rationality constraints relaxed. 16

There is one other small sample problem that can arise in estimation here. In cases where the number of lags (N) in the unemployment or output equation is large, many degrees of freedom are used up in estimation and yet there is no allowance for this loss of degrees of freedom in the likelihood ratio statistics. This leads to the danger that spurious rejections of the null hypothesis might occur because the small sample distribution of the test statistics differ substantially from the asymptotic distributions in this case. 17 In order to avoid this problem, the models discussed

${ }^{16}$ Research in progress with Andrew Abel discusses the identification of parameters in the systems estimated avove and shows when seperate tests of neutrality and rationality are feasible. The identification conditions for the seperate tests are met in the models of this paper. This research also shows that the nesting of hypothesis tested above could proceed with a different ordering, but that used here makes more economic sense.

17 The type of problem I am worried about here becomes more obvious if we look at the following example. In an OLS regression a test of restrictions 
in the text are estimated with the restriction that the unanticipated money growth coefficients $\left(\beta_{i}\right)$ lie along a fourth order polynomial with an endpoint constraint. This parameterization has the advantage that it uses up fewer degrees of freedom, yet, as the comparison between results in the text and Appendix II indicate, it does not significantly affect the fit of the output and unemployment equations, nor does it appreciably alter the coefficient estimates or their asymptotic standard errors. ${ }^{18}$

can be carried out with a finite sample test, the $F$, or with an asymptotic test, the likelihood ratio. Asymptotically, the test statistics have the same distribution, but misleading inference with the likelihood ratio statistic can easily result in small samples. The F-statistic is calculated as,

$$
F(q, d f)=\left(\left(\frac{S_{S R}^{c}-S S R^{u}}{S S R^{u}}\right) \frac{d f}{q}\right.
$$

the likelihood statistic is: $n \log \left(\mathrm{SSR}^{\mathrm{c}} / \mathrm{SSR}^{\mathrm{u}}\right.$ where $\mathrm{d} f=$ the degrees of freedom of the unconstrained model, $n=$ the number of observations, $\mathrm{q}=$ the number of constraints. For over 100 degrees of freedom $q F(q, d f)$ is nearly distributed as $\chi^{2}(q)$, and for small percentage differences, $S_{S R}{ }^{c}-S S R^{u}$ is approximately equal to $\log \left(S S R R^{c} / S S R{ }^{u}\right.$. $\operatorname{SSR}^{\mathrm{u}}$

Inference with the F-statistic in the case of over 100 degrees of freedom then involves approximately the comparison of $\mathrm{df}\left(\log \left(\mathrm{SSR}^{\mathrm{C}} / \mathrm{SSR}^{\mathrm{u}}\right)\right)$ with the $x^{2}(q)$ distribution. Even in the case where df is large, if $n / d f$ is substantially greater than one the likelihood ratio statistic will reject the null hypothesis far more often than will the F. In the case of the unemployment or output model with no PDI constraints and $N=20$, the degrees of freedom of the unconstrained model for the joint or rationality tests is 111 while the number of observations is 184. The $\mathrm{n} / \mathrm{df}$ of 1.7 in the case demonstrates that there potentially is a serious small sample bias in the likelihood ratio test when this many degrees of freedom are used up.

18 18 Likelihood ratio tests of the polynomial distributed lag (PDL) constraints do not reject the null hypothesis that these constraints are valid. For model $2.1 x^{2}(4)=3.34$, and for $2.2 \chi^{2}(4)=1.56$, the critical value of $x^{2}(4)$ at the 5\% level is 9.49. For $4.1 \chi^{2}(17)=12.94$ and for $4.2 \chi^{2}(17)=13.76$, while the critical value of $x^{2}(17)$ at $5 \%$ is 27.59 . 
One remaining issue concerning estimation needs to be discussed. In this paper we are particularly interested in obtaining correct test statistics for our models, so it is critical that the suprious regression phenomenon [Granger and Newbold $(1974)$ ] be avoided. 19 Therefore, particular attention must be devoted to the serial correlation properties of the error term, $\varepsilon$, of equation (4) and (6). This is especially important because no theoretical argument guarantees that it will be white noise and evidence in Barro and Rush (1978) indlcates that it has appreciable serial correlation when postwar quarterly data is used. In the estimation here, the error term, $\varepsilon$, is assumed to be a fourth order AR process. This specification for the error term was chosen because fourth order autoregressions usually eliminate most serial correlation in quarterly, macro time-series. Indeed, Durbin-Watson statistics and the residual autocorrelations of the estimated model indicate that this serial correlation correction is successful in reducing the residuals to white noise. 20

\section{${ }^{19}$ Also see Plosser and Schwert (1978).}

${ }^{20}$ In the models estimated here, the Durbin-Watson statistics for $\varepsilon_{t}$ range from 1.82 to 2.15 , none of which indicates the presense of first order serial correlation. Furthermore, the Box-Pierce. (1970) Q-statistic for the first twelve autocorrelations of $\varepsilon_{t}$ range from 5.25 to 12.42 so that the null hypothesis that these twelve autocorrelations are zero cannot be rejected at the 5 percent level. (The critical $Q(12)$ at 5 percent is 15.50. ) 
THE SPECIFICATION OF THE MONEY GROWTH EQUATION

As the debate between Small (1979) and Barro (1979), as well as Germany and Srivastava (1979), have shown, the specification of the money growth equation (2) is critical to the ability to explain the postwar movements in unemployment with only unanticipated movements in money growth. Indeed, Barro (1977, 1978), Leiderman (1978), Germany and Srivastava (1979) and Small's (1978) specification of the money growth equation are flawed. Rational expectations theory implies that the anticipated money growth variable in equation ( 1 ) is an optimal, one-period-ahead forecast, conditional on available information. Thus an appropriate prediction equation should rely only on lagged explanatory variables on the right-hand-side of (2). The money growth specification used in the studies discussed here violates this principle because it includes the current value of the deviation of federal expenditures from normal (FEDV) as an explanatory variable. 21 In predicting money growth at time $t$, the market does not have complete knowledge of the actual value of this FEDV variable at time $t$, and this leads to a misspecification in the money growth equation which is potentially serious. It is easy to show that this type of misspecifi-

${ }^{21}$ Another way to see this point is as follows. The money growth equation with FEDV $t$ is

$$
M G_{t}=z_{t} \gamma+\delta F E D V_{t}+u_{t}
$$

where, $M_{t}$ is money growth at $t, z_{t}$ is, as in the text, a vector of variables known at time $t-1$ and $\gamma$ and $\delta$ are coefficients. Then unanticipated money growth is :

$$
\begin{aligned}
M G_{t}-E_{t-1} M G_{t} & =M G_{t}-\left(z_{t} \gamma+\delta E_{t-1} F E D V_{t}\right) \\
& =\left(M G_{t}-z_{t} \gamma-\delta F E D V_{t}\right)+\delta\left(F E D V_{t}-E_{t-1} F E D V_{t}\right) \\
& =u_{t}+\delta\left(F E D V_{t}-E_{t-1} F E D V_{t}\right)
\end{aligned}
$$


cation leads to invalid tests of rationality in an efficient markets framework, $^{22}$ and for similar reasons it will also invalidate tests of the propositions embodied by the MRE hypothesis. Hence, this misspecification casts doubts on this previous empirical work.

In this paper, the specification of the money growth equation is approached in quite a different way from that used by Barro (1977) and the other studies mentioned above. The reason for this is as follows. It is difficult on prior grounds to exclude any particular piece of information available at time $t-l$ as a useful predictor of a policy variable. For example, even though there is no strong theoretical reason for expecting a particular variable to enter the $\mathrm{Z}$ vector of money growth equation (2), it might be a useful predictor of money growth because the personali-

where $E_{t_{-1}}$ is the expectations operator conditioned on information available at $t$ Ime $t-1$. The above expression is not equivalent to the residuals from the money growth equation, for it differs by an expression involving the unanticipated FEDV . Clearly then, using residuals from the money growth equation to proxy for unanticipated money growth is valid when only lagged variables are included in this equation or if there are no errors

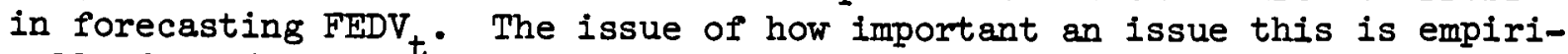
cally depends on the magnitude of the forecasting errors for FEDV $t$ relative to the u's.

${ }^{22}$ In an efficient markets framework with equation (2) and an equation (4) where only the contemporaneous $M-M$ enters, Abel and Mishkin (1979) have shown that the test of the equality of $\gamma$ in (2) and (4) is asymptotically equivalent to the test that $y_{t}-y_{t}^{*}$ is uncorrelated with any linear combination of $\mathrm{Z}_{t}$. Market efficiency, however, does not exclude the correlations of $y_{t}-y_{t}^{*}$ with current variables. Hence, if a current variable only known at $t_{i m e} t$ is included in $z_{t}$, the market could be efficient and rational yet we might expect the rejection of the cross-equation, market efficiency constraints. Thus including a current variable in $z_{t}$ renders
this test invalid. 
ties involved in policy making could be such that they react to this variable for their own inscrutable reasons. Thus, the economic theory that a researcher uses to explain his money growth specification might be relatively unimportant in deciding on the validity of his particular specification versus another researcher's.

The discussion above suggests that an atheoretical statistical procedure might be superior to economic theory for deciding on the equation (2) specification. The procedure used here amounts to running multivariate, Granger (1969) tests. Note that the issue here is the predictive content of information - - which is what Granger tests are really meant to analyze - - and it does not involve the tricky concept and issue of economic causality which has led to so much confusion in the literature. ${ }^{23}$ The multivariate time-series specifications for equation (2) are chosen using the following criterion. Money growth can be regressed on its own four lagged values (again to insure white noise residuals) as well as on four lagged values of a wide ranging set of macro variables, such as: the quarterly MI or M2 growth rate, the inflation rate, the growth rate of nominal GNP, the growth rate of real GNP, the unemployment rate, the treasury bill rate, the growth rate of real government expenditure, the high employment surplus, the growth rate of the federal debt and the balance of payments on current account. This particular list of variables was chosen

${ }^{23}$ See Zellner (1979) for a discussion of Granger "causality" and the pitfalls of these tests. 
because they are readily available information which many researchers (see Fair (1978) and the references therein) have cited as being of potential use in explaining policy responses, in particular that of monetary policy. The four lagged values of each of these variables are retained in the equation only if they are fointly significant at the five percent level or higher. The major advantage of this procedure is that it imposes a discipline on the researcher that prevents his searching for an equation (2) specification that leads to results that confirm his prior on the validity of the MRE hypothesis.

Note that the resulting forecasting equations derived from this procedure will only contain explanatory variables in $z_{t}$ that are available at time t-1. Thus the objection to the forecasting specifications in the previous empirical work on the MRE hypothesis will not be present here. In addition, this approach leads to a very different specification for the money growth equation than has been used previously, and the resulting estimates of the (2) and (4) system will thus provide new information. 
SPECIFICATION OF THE LAG LENGTH IN THE MRE EQUATION (I)

A primary objective of this study is to obtain nore information on the robustness of results with the MRE model of equation (1). As has been discussed by McCallum (1979), the theoretical framework underpinning equation (1) does not specify what the lag length, $\mathbb{N}$, should be on unanticipated * money growth. The standard criterion for chosing this lag length is empirical: for example, Barro (1977) and Rush (1978) choose the lag length on the basis of excluding lagged unanticipated money growth variables if their coefficients are not significantly different from zero in the model of equation (1). This yields a lag length which is fairly short - - two years or under.

There are several reasons why this paper does not restrict itself to estimation of models with only this short lag length. Research which studies an equation of the form of (1) with other variables besides money growth as the aggregate demand policy variables finds that unanticipated aggregate demand variables lagged as far back as twenty quarters are significantly correlated with output and unemployment. 24 Thus, it is plausible that estimating models with longer lags on unanticipated money growth might reveal interesting new information.

Furthermore, if the MRE hypothesis is not valid, then choosing the lag

${ }^{24}$ See Gordon (1979) and Mishkin (1980c) 
length from a model like equation ( 1 ) is inappropriate if we are interested in testing this hypothesis. There is a general econometric principle which supports testing of models with longer lag lengths. The addition of irrelevant variables to an estimated model only has the disadvantage of a potential decrease in the power of the likelihood ratio tests so that we would be less likely to reject the null hypothesis if it were untrue: it will not result in incorrect test statistics. However, excluding relevant variables will render test statist1cs invalid. With this view, experimentIng with plausible, less restrictive, models is an appropriate strategy for analyzing the robustness of results.

Now with the preliminaries out of the way, we can turn to the empirical tests. 
THE RESULTS

The tests of the MRE hypothesis in the text use seasonally adfusted, postwar quarterly data over the 1954-76 period and the joint estimation procedures outlined in the previous section:- Following Barro and Rush (1978), the data are seasonally adjusted and Ml growth is chosen as the monetary variable. The data are discussed in more detail in the data appendix. Again in pursuit of information on robustness, both output and unemployment models are estimated in this paper (i.e., where $\mathrm{y}_{t}$ is the quarterly unemployment rate or the log of real GNP). The natural level of unemployment or output, $\mathrm{y}_{t}^{*}$ is estimated as a time trend here as in Barro (1978). A more complicated Barro (1977) specification, has been avoided, because as is indicated by Small (1979) and Barro (1979), its validity is doubtful.

The first step in pursuing the MRE tests is to specify the variables in the money growth equation (2). The multivariate, Granger procedure outlined in the previous section yields an $\mathrm{Ml}$ money growth equation that has the following variables in the Z-vector: 4 lagged values of MI growth, the 90-day treasury bill rate and the high-employment surplus. The resulting ordinary least squares results with standard errors in parentheses are as follows: 
(10)

$$
\begin{aligned}
& \mathrm{MIG}_{t}=\begin{array}{l}
.0031+672 \mathrm{MIG}_{\mathrm{t}-1}+ \\
(.0012)(.1131)
\end{array} \\
& \begin{array}{l}
-.0353 \mathrm{MIG}_{t-3^{-}} \\
(.1358) \\
(.1181)
\end{array} \\
& +.5918 \mathrm{RTB}_{t-2}-.1897 \mathrm{RTB}_{t-3}+.0091 \mathrm{RTB}_{t-4} \\
& \begin{array}{lll}
(.1640) \quad(.1729) \quad(.1134)
\end{array} \\
& -\underbrace{.2055 \text { SURPLUS }_{t-1}+}_{(.0761)} \underset{(.0844)}{.0996 \text { SURPLUS }_{t-2}} \\
& +\quad .0387 \text { SURPLUS }_{t-3}-.0776 \text { SURPLUS }_{t-4} \\
& (.0880) \quad(.0761)
\end{aligned}
$$

$\mathrm{R}^{2}=.6601$ Standard Error $=.0042 \quad$ Durbin Watson $=1.98$

where

$$
\begin{aligned}
& \text { MIG = average quarterly rate of MI growth, } \\
& \text { RTB = average treasury bill rate, } \\
& \text { SURPLUS = high-employment surplus. }
\end{aligned}
$$

Table 1 provides F-statistics of the joint significance test for whether the four lagged values of each variable in the list of potential explanatory variables should be included in this regression model.

Note that in contrast with Barro's (1977), and Barro and Rush's (1978) specification, netther real government expenditure nor unemployment are significant explanatory variables. Chow (1960) tests which split the sample in equal halves indicate that this model has the desirable property that stability of the coefficients cannot be rejected at the $5 \%$ level. 25

${ }^{25}$ The F-statistic for the Chow test is $F(13,66)=1.37$ while the critical F at 5 percent is 1.88 . 
Table 1

Joint Tests for Significant Explanatory Power in (10)

of Four Lags of Each Variable

\begin{tabular}{lcc}
\hline \hline Variable & F-statistic & Marginal \\
MIG & 15.89 & $1.4 \times 10^{-9}$ \\
RTB & 5.28 & $8.0 \times 10^{-4}$ \\
SURPLUS & 2.56 & .0449 \\
UN & 1.66 & .1682 \\
RGNP & .82 & .5165 \\
$\pi$ & 1.69 & .1612 \\
G & .13 & .9710 \\
BOP & 1.28 & .2855 \\
GDEBT & 1.52 & .2050 \\
M2G & 1.25 & .2973 \\
NGNP & 1.09 & .3677 \\
\hline \hline
\end{tabular}

The F-statistic tests the null hypothesis that the coefficients on the 4 lagged values of each of these variables equals zero. The marginal significance level is the probability of finding that value of $F$ or higher under the null hypothesis. For MIG, RTB, and SURPLUS, the F-statistic is calculated as $F(4,79)$. For the other variables the F-statistic is $\mathrm{F}(4,75)$.

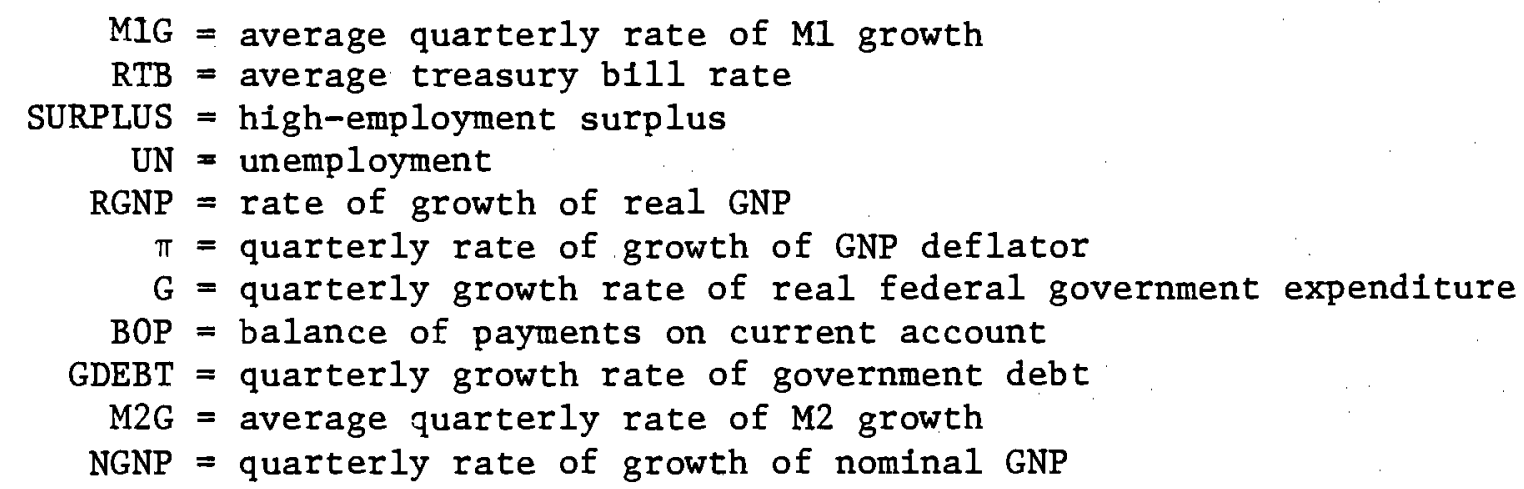


Table 2 contains estimates of the quarterly output and unemployment equations which have been estimated from the (2) and (4) system, imposing the cross-equation constraints that the $\gamma$ are equal in both equations. The resulting $\gamma$ estimates are not reported in Table 2 and the tables that follow because they are similar to the results in (10) and provide little new information. A specification with the current and seven lagged values of unanticipated $M l$ money growth is analyzed first for two reasons: This lag length has been previously used on quarterly data by Barro and Rush (1978), and the coefficients of unanticipated money growth lagged more than seven quarters are found to be insignificantly different from zero. Despite the use of a substantially different specification for the money growth equation, the Table 2 results are quite close to those of Barro and Rush (1978). The models here fit the data well as in Barro and Rush, and the unanticipated money growth variables also have significant explanatory power, with many of their coefficients' asymptotic t-statistics greater than four in absolute value. Even more striking is the similarity of the parameter estimates. Not only do the Table 2 models display the same pattern of serial correlation in the residuals as the Barro and Rush results, but also the lag structure has the same humped pattern and peaks at identical lags. 


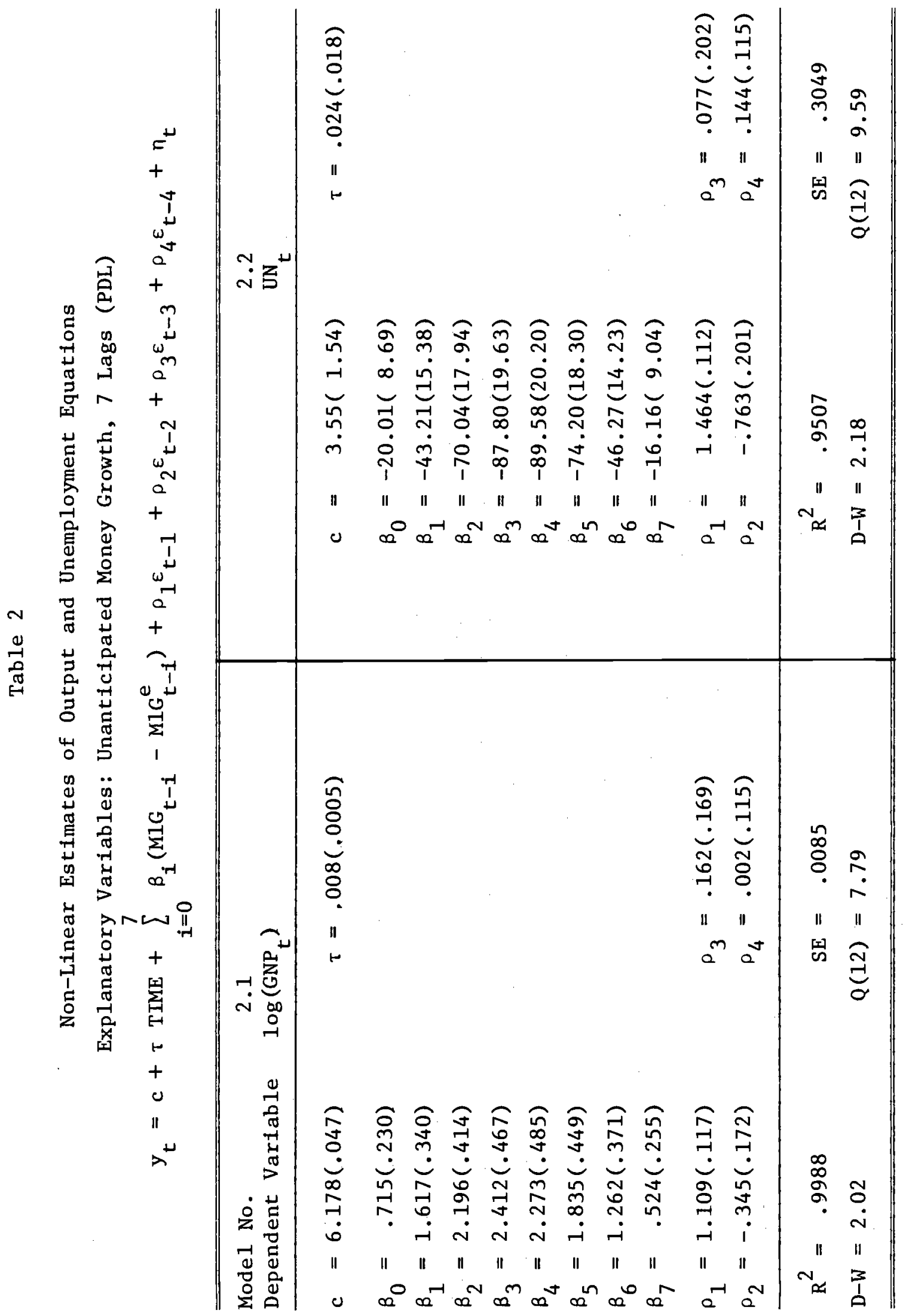




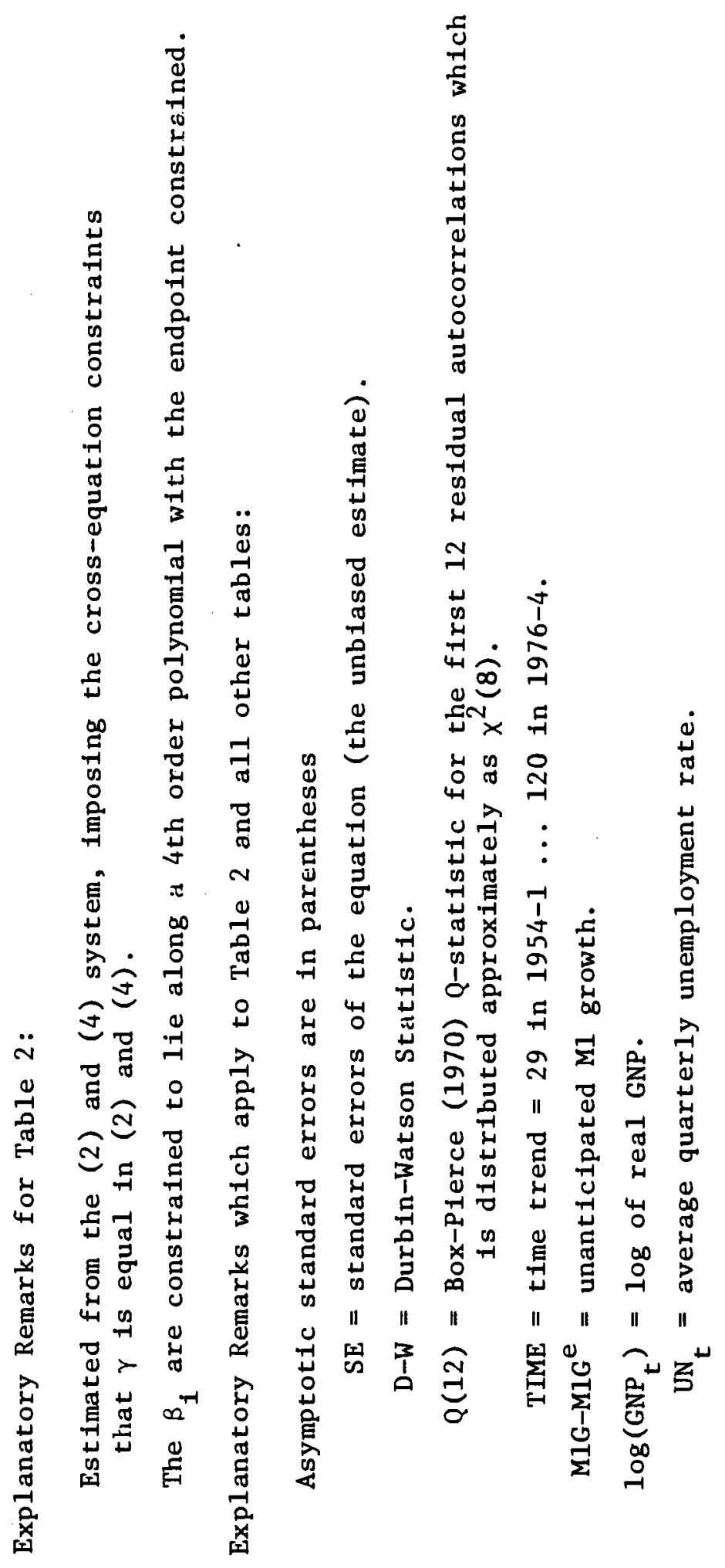


Table 3

Likelihood Ratio Tests for the Models of Table 2

\begin{tabular}{lcc}
\hline \hline Model No. & 2.1 & 2.2 \\
\hline Joint Hypothesis & $\chi^{2}(16)=22.69$ & $\chi^{2}(16)=22.80$ \\
Likelihood Ratio Statistic & .1222 & .1192 \\
Marginal Significance Level & $\chi^{2}(4)=3.36$ & .0464 \\
Neutrality & .4993 & $\chi^{2}(4)=9.67$ \\
Likelihood Ratio Statistic & & \\
Marginal Significance Ratio & $\chi^{2}(12)=19.44$ \\
Rationality & .0784 & $\chi^{2}(12)=13.31$ \\
Likelihood Ratio Statistic & & .3466 \\
Marginal Significance Level & & \\
\hline \hline
\end{tabular}


The fact that the Table 2 results are so close to those of Barro and Rush in an important finding. Because the econometrician's life is made difficult by the absence of direct measures of expectations for most variables in the economy, poor speciflcation of expectations formation is always a danger in this line of research. Although, misspecification of money growth equation (2) would lead to an error-in-variables bias in the eoefficients of the unemployment or output equation, the question is how severe this bias would be. Money growth is apparently quite hard to forecast so that the variance of the true forecast error could be substantial. In addition, Feige and Pierce (1976) have made the argument that autoregressive expectations models might be "economically rational" because other information might have little incremental predictive power once the past history of the variable to be predicted is taken into account. 26 This argument implies that the variance of the measurement error in the money growth expectations model used here may be small in relation to the variance of the forecast error. If this occurs, then the errors-in-variable bias may be negligible and should not be an important problem in this research.

The similarity of the results in Table 2 and those of Barro and Rush lends some support to this view, because, except for past money growth,

${ }^{26}$ Note that Sims (1977) has shown that there are some dangers in the statistical techniques used by Feige and Pierce (1976). Therefore, we should be cautious in interpreting their empirical evidence as supporting this conclusion. 
quite different information is included in the money growth equation here. Other research with a similar system to that estimated here also finds that changing the specification of the time-series model used to describe money growth expectations does not lead to substantial differences in the results. 27

The likelihood ratio tests in Table 3 are not too unfavorable to the MRE hypothesis. The tests for the 2.1 output model do not call for rejection of either neutrality or rationality propositions, nor the joint hypothesis. The marginal significance level of each test is defined as the probability of finding that value of the likelihood ratio statistic or higher under the null hypothesis, where a value less than .05 would indicate a rejection of the null hypothesis at the five percent level. None of the marginal significance levels for the model 2.1 tests is below .05. The unemployment model 2.2 is not quite as supportive of the MRE hypothesis: the foint hypothesis and rationality are not rejected at the $5 \%$ level, yet neutrality is barely rejected at $5 \%$ in this case.

We can achieve a deeper understanding of the test results in Table 3 by studying the estimated output and unemployment equations where current and lagged anticipated money growth are added as explanatory variables. Table 4 contains the results from the (2) and (6) system, estimated iteratively, with rational expectations imposed. The 4.1 results illustrate why the neutrality proposition is not rejected in the output equa-

27 See Mishkin (1980a). Mishkin (1978) analyzes an efficient-markets model similar to equation (1) where unanticipated short rates are an explanatory variable. In this model, use of an autoregressive specification to describe short rate expectations leads to results similar to those obtained with the use of a forward rate to describe short-rate expectations. This is even stronger evidence that the view promoted above is credible, since forward rates are a more direct measure of expectations. 


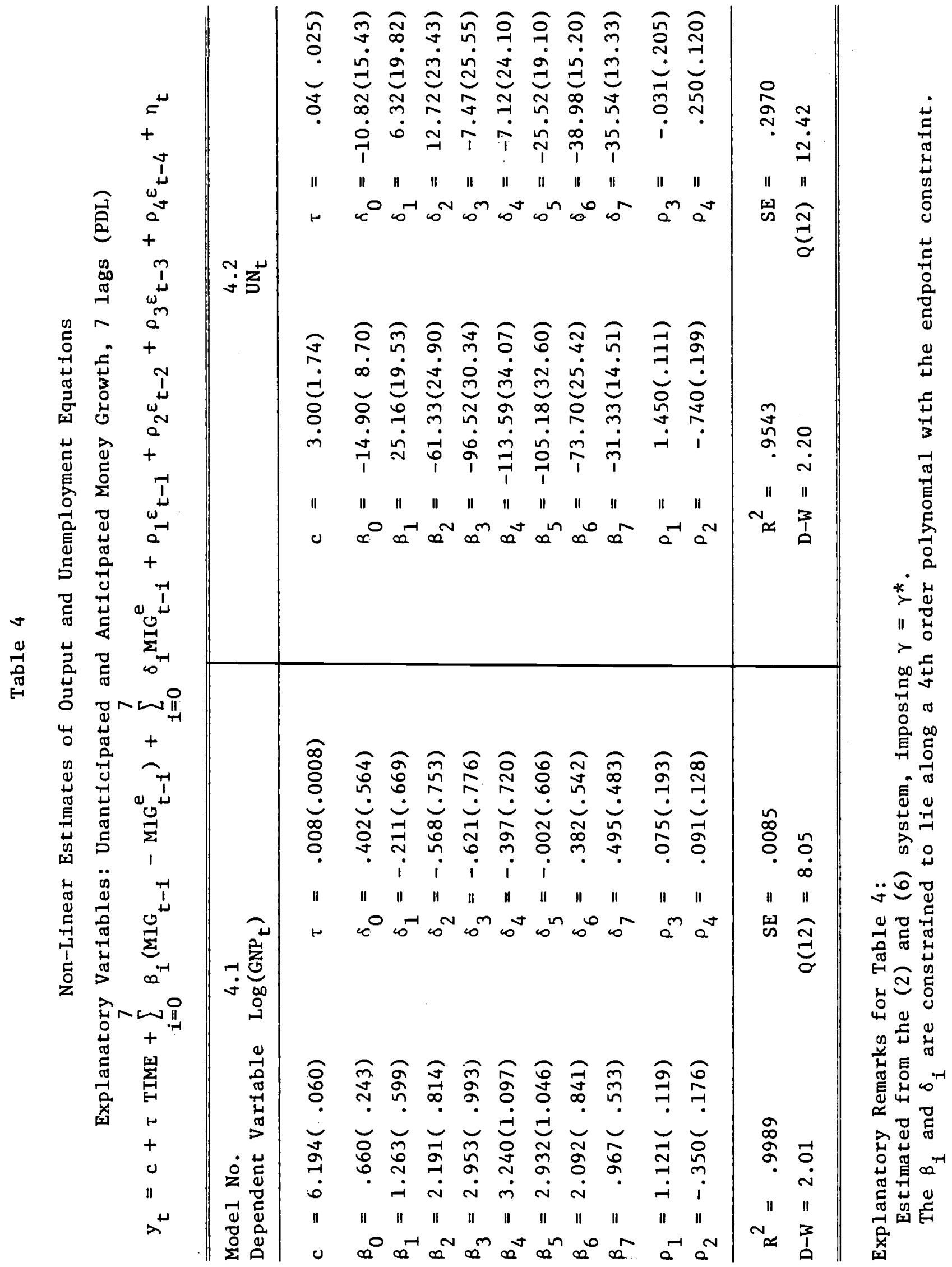


tion. The coefficients on anticipated money growth have no obvious pattern, are never significantly different from zero and are in seven out of eight cases smaller in absolute value than their asymptotic standard errors. However in the unemployment equation, some coefficients on anticipated money growth are significantly different from zero at the five percent level, and this leads to the rejection of neutrality in Table 3. Here, the last two lag coefficients on anticipated money growth are the most significant with asymptotic t-statistics exceeding 2.5. This creates the suspicion that even longer lag lengths for unanticipated and anticipated money growth may lead to strong rejections of the MRE hypothesis.

Table 5 contains estimates of the output and unemployment equations in which longer lags (twenty) of unanticipated money growth are used as explanatory variables. Although in neither case are coefficients on unanticipated money growth lagged more than 7 quarters significantly different from zero, as is evident in Table 6, strong rejections of the MRE hypothesis now occur. The unemployment model rejects the joint hypothesis of neutrality and rationality, while the seperate test of the component hypotheses indicate that the main contributor to the rejection is the neutrality constraints: rationality of expectations is not rejected at the 5\% level while neutrality is. The results on the output model are even more negative. The probability of obtaining that value of the likelihood ratio statistic or higher under the null joint hypothesis is only 1 in 5000. Here the contribution of each set of constraints to this rejection is nearly equal with both the rationality and neutrality constraints refected at the $1 \%$ level. Because excluding relevant variables 


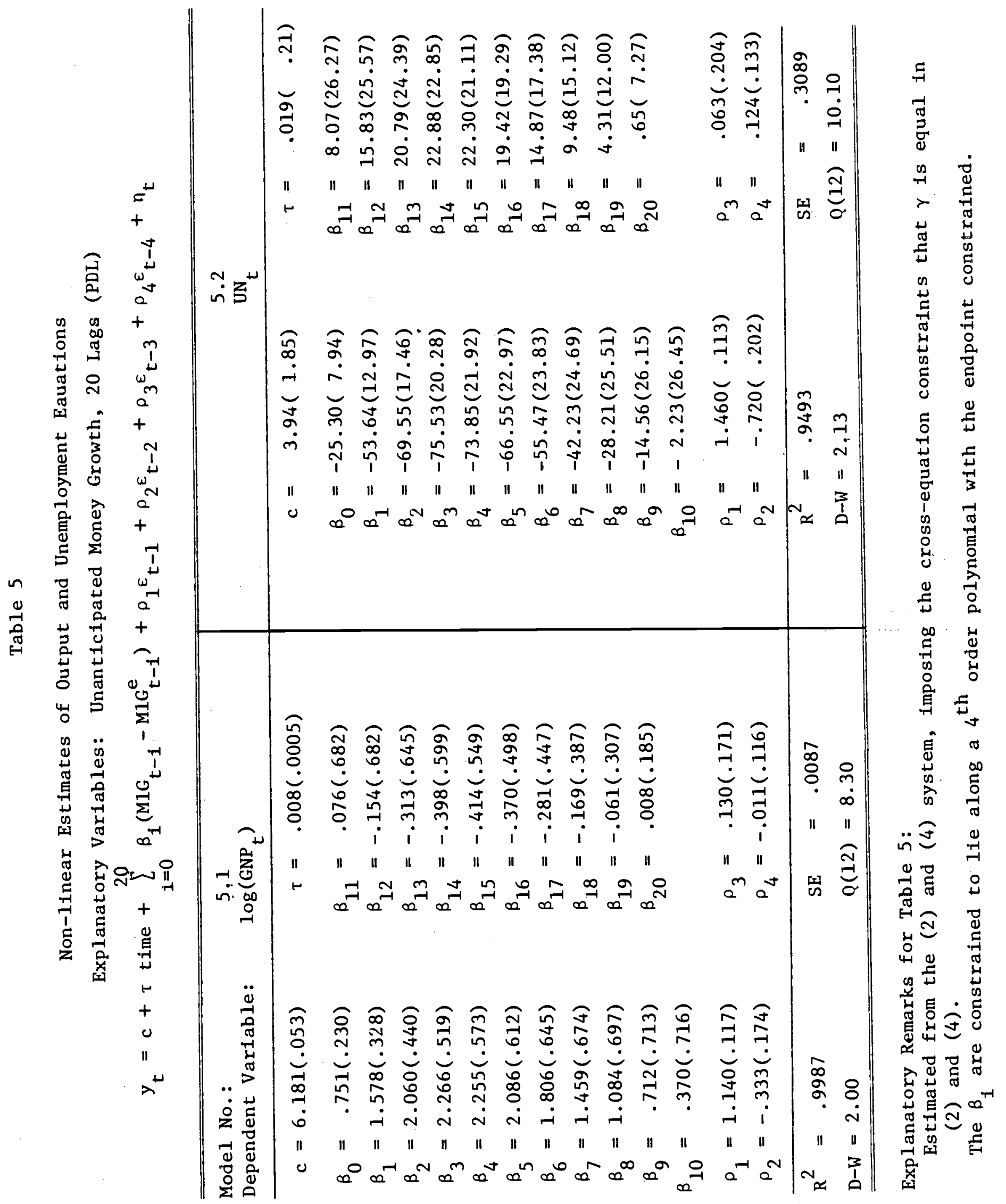


Table 6

Likelihood Ratio Tests for the Models of Table 5

\begin{tabular}{lcc}
\hline Model No. & 5.1 & 5.2 \\
\hline Joint Hypothesis & $\chi^{2}(16)=43.83$ & $\chi^{2}(16)=31.54$ \\
Likelihood Ratio Statistic & .0002 & .0114 \\
Marginal Significance Level & $\chi^{2}(4)=15.45$ & $\chi^{2}(4)=12.08$ \\
Neutrality & .0038 & .0168 \\
Likelihood Ratio Statistic & \\
Marginal Significance Level & $\chi^{2}(12)=29.17$ \\
Rationality & .0037 & $\chi^{2}(12)=19.89$ \\
Likelihood Ratio Statistic \\
Marginal Significance Level
\end{tabular}


from a model will result in inconsistent test statistics, but including Irrelevant variables will at worst only reduce the power of the tests, the Table 6 results are damaging to the view that empirical evidence supports the MRE hypothesis. Indeed it appears that the only reason that the earlier 2.1 and 2.2 models are not unfavorable to the MRE hypothesis is due to misspecification which ylelds inconsistent test statistics.

Table 7 and 8 contain the estimates of the Table 5 models which add twenty lags of anticipated money growth to the list of explanatory varibles. As we would expect from Table 6, anticipated monetary policy matters in these results. Many of the coefficients on anticipated money growth are significantly dfferent from zero at the $1 \%$ level, with some asymptotic t-statistics even exceeding four in absolute value. of course these coefficients could be statistically significant, yet unimportant from an economic viewpoint. This is clearly not the case in Tables 7 and 8. Not only do the anticipated coefficients tend to be greater in absolute value than their unanticipated counterparts, but generally they also have higher asymptotic t-statistics. In fact, in Tables 7 and 8 , only one out of twenty-one $\beta$-coefficients is statistically signiflcant versus nearly half of the $\delta$-coefficients. Contrary to what is implied by the MRE hypothesis, anticipated monetary policy does not appear to be less important than unanticipated monetary polfcy; rather the opposite seems to be the case. ${ }^{28}$

${ }^{28}$ Most structural macroeconometric models in use do not make a distinction between anticlpated and unanticipated monetary policy and are not capable of lending an interpretation to the lag patterns of the $\delta$ 's versus the $\beta^{\prime} s$ in Table 7 and 8 . It is not obvious what form these lag patterns should take in a model where expectations are rational, yet anticipated 


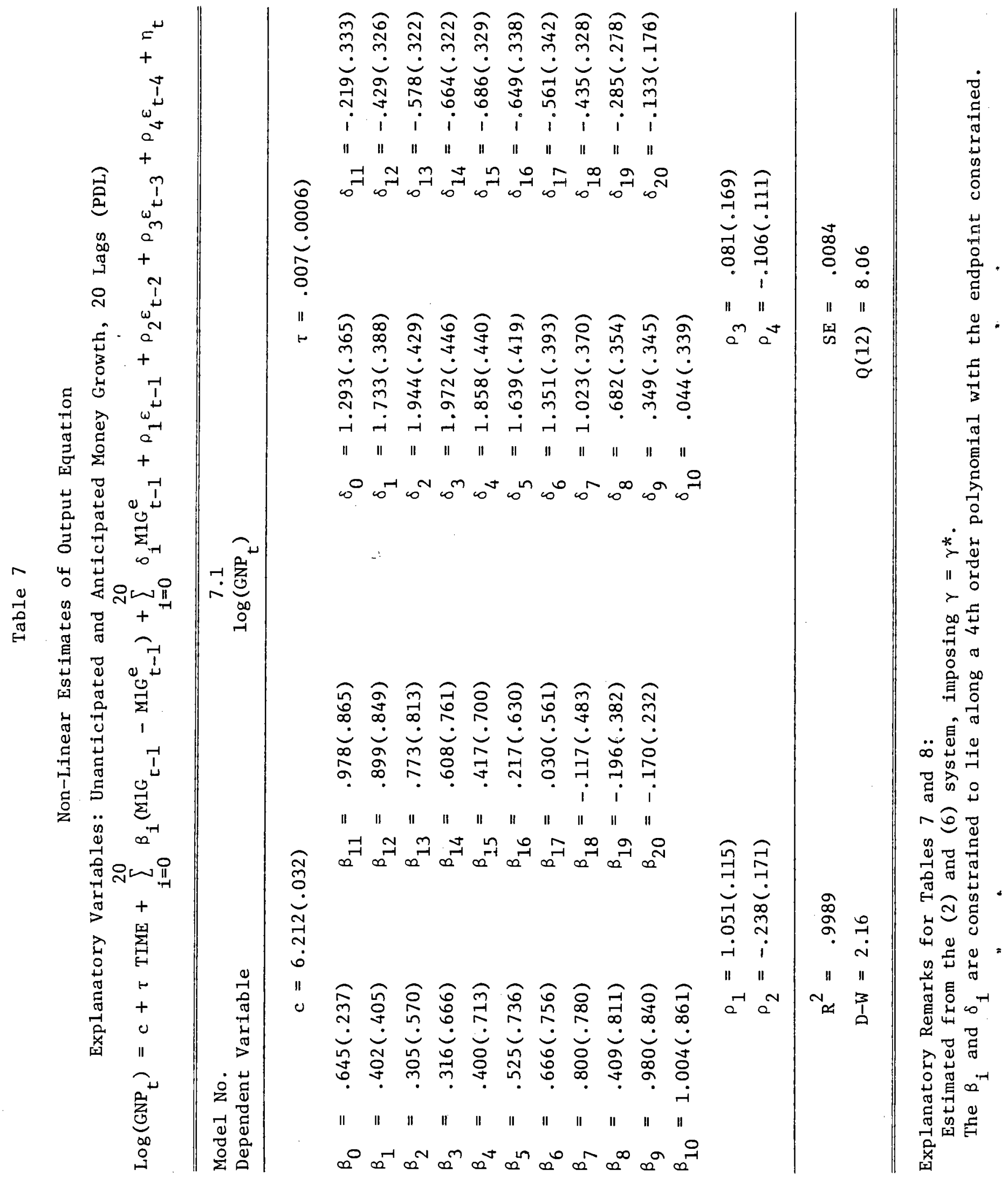




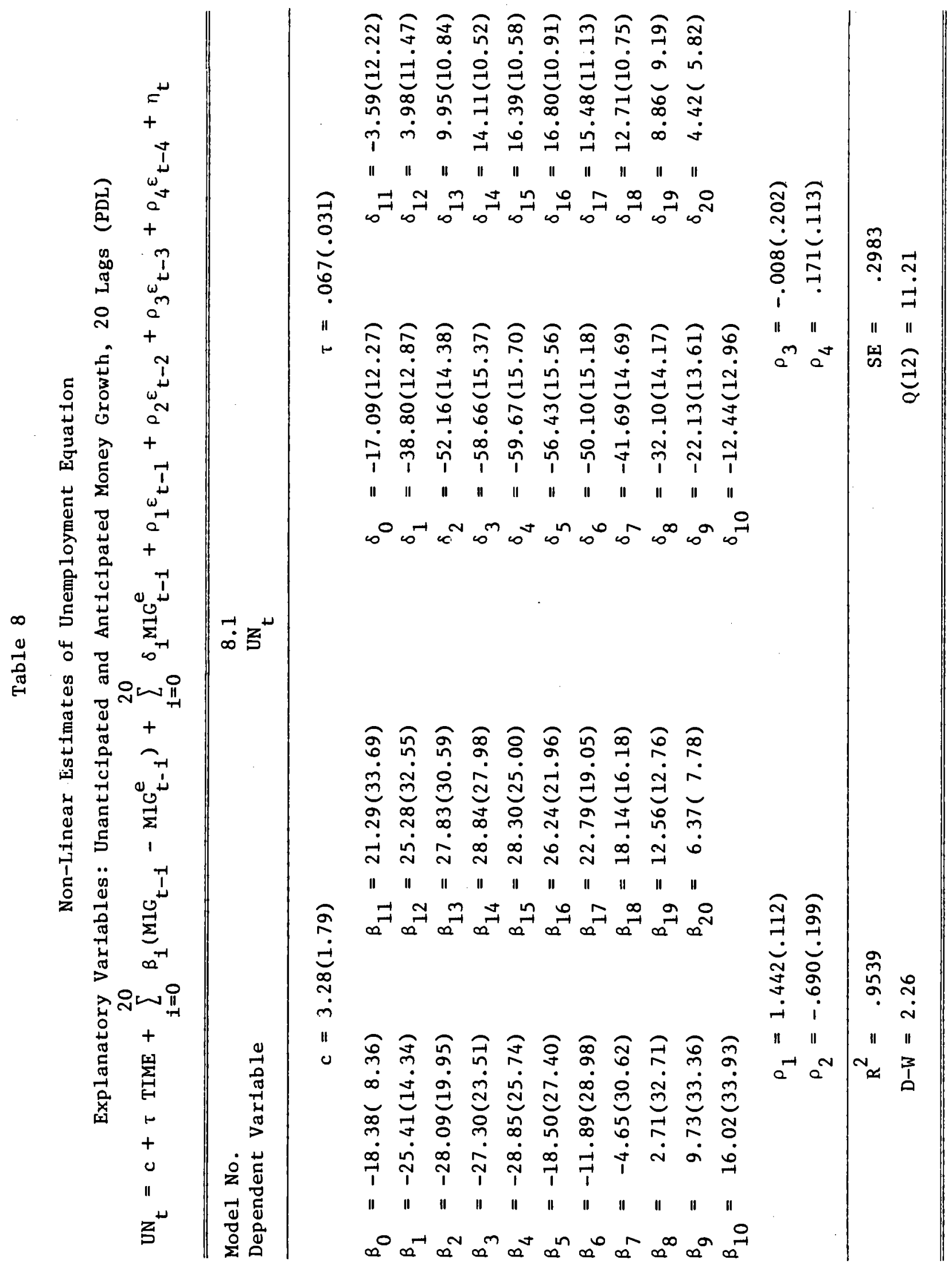


Output and unemployment equations were also estimated using M2 growth rather than MI growth as the policy variable. These results, which are not reported here in the interests of conserving space, indicate that MI growth versus M2 growth in the estimated models does not lead to different conclusions. $^{29}$ However, using unanticipated M2 growth rather than MI growth does lead to some deterioration in the fit of the equations as well as lower asymptotic t-statistics. The use of seasonally adjusted versus seasonally unadjusted data also does not appear to be an important issue in the empirical work here. For example when seasonally unanadjusted MI data is used to estimate output and unemployment models rather than seasonally adjusted data, the results are not appreciably different. 30 other empirical work which uses a model resembling the constrained (2) and (4) system also does not find that using seasonally adjusted versus unadjust-

monetary policy matters. Econometric models of this type are just now being developed, Taylor (forthcoming) for example, but to my knowledge simulation results which display the reduced form $\beta$ and $\delta$ coefficients are not yet available.

29 For example, the 2.1A M2 model does not lead to rejection of the joint hypothesis. Here the speciflcation of the M2 time-serles model was also generated with the multivariate Granger (1969) procedure discussed in the text. The likelihood rat1o statistic is $x^{2}(15)=18.1$ with a marginal significance level of .26. However, the M2 results for the additional models explored in this paper are also as negative to the MRE hypothesis. For example, the $4.1 \mathrm{~A}$ model with $\mathrm{M} 2$ data leads to a likelihood ratio statistic for the joint hypothesis of $x^{2}(28)=58.90$ with a marginal significance level of .0006 .

30 Because a fourth order autoregression is not sufficient to reduce the seasonally unadjusted Ml growth to white noise, values of the unadjusted Ml growth for lags 5 through 8 replaced the SURPLUS variables in the equation (2) specification. The coefficlents and asymptotic standard errors of the 2. IA model estimated with unadjusted data are close to those reported in Table 2 and the likelihood ratio statistic of the joint hypothesis in this case is $x^{2}(19)=29.75$ with a marginal significance level of .0551. The unadjusted results for the 4.1A model are also unfavorable to the MRE hypothesis as is true 
ed data appreciably affects the results. 31

of the Appendix II results: the likelihood ratio statistic for the joint hypothesis is $\chi^{2}(33)=62.65$ with a marginal significance level of .0014 .

31 Mishkin (1980a, 1980b) 
The title of this paper asks the question "Does Anticipated Monetary Policy Matter?" The empirical analysis here responds with a strong yes. A closer look at models with money growth as the aggregate demand policy variable reveals that the neutrality proposition of the MRE hypothesis is rejected, particularily when long lag lengths are allowed to enter output and unemployment equations. Furthermore, contrary to the implications of the MRE hypothesis, unanticipated movements in monetary policy do not have a larger impact on output and unemployment than anticipated movements.

The other proposition embodied in the MRE hypothesis, that expectations are rational, fares better in the empirical tests here. Although the rationality hypothesis does not come out unscathed - - there is one rejection at the 1 percent level- - none of the other rationality tests in the text reject at the 5 percent level. 32 When the MRE component hypotheses of rationality and neutrality are tested jointly, strong rejections occur in the output and unemployment models with long lag lengths. In one case, the probability of finding that value of the likelihood ratio statistic under the null joint hypothesis was only 1 in 5000 .

\section{2}

I do not cite the rationality test results in Appendix II because, as the discussion in Section II indicates, they may not be as reliable, In further work on the MRE hypothesis (Mishkin (1980c)) with inflation and nominal GNP growth as aggregate demand policy variables, the results are even more favorable to the rationality hypothesis: there are no rejections at the 5\% level of the rationality constraints. The results on neutrality, however are less favorable, with even stronger rejection of the neutrality constraints than are found here. 
There is one qualification of the results that warrants further discussion. This paper has followed the previous research in this area by using the identifying assumption that the output and unemployment equations are true reduced forms. It is not clear whether the invalidity of this assumption might lead to rejections of the MRE hypothesis even if it were true. Thus, the results here are by no means a definitive rejection of this hypothesis. However, this work does cast doubt on previous evidence - - also of a reduced form nature - - that is cited as supporting the view that only unanticipated monetary policy is relevant to the business cycle. 
APPENDIX I

VARIABLES AND SOURCES OF DATA

MIG = average growth rate (quarterly rate) of $\mathrm{Ml}$, calculated as the change in the $10 \mathrm{~g}$ of quarterly MI (from the NBER data bank)

M2G = average quarterly growth rate (quarterly rate) of M2, from same source and calculated in same way

SURPLUS = high employment budget surplus from NBER data bank (in trillions \$)

RTB = average treasury bill rate at an annual rate (in fractions), from the MPS data bank

$\pi=$ inflation (quarterly rate), calculated as the changes in the log of the GNP deflator (from the MPS data bank)

$G=$ growth rate (quarterly rate) of real federal government expenditure, calculated as the change in the log of real federal expenditure (from the MPS data bank)

GNP = real GNP (billions 1972 \$), from the MPS data bank

UN = average quarterly unemployment rate (from the MPS data bank)

NGNP = growth rate (quarterly rate) of nominal GNP, calculated as the change in the $10 \mathrm{~g}$ of nominal GNP, from the MPS data bank.

The other variables used in the search procedure for the forecasting equations were obtained from the NBER data bank. 
Freely Estimated Output and Unemployment Equations

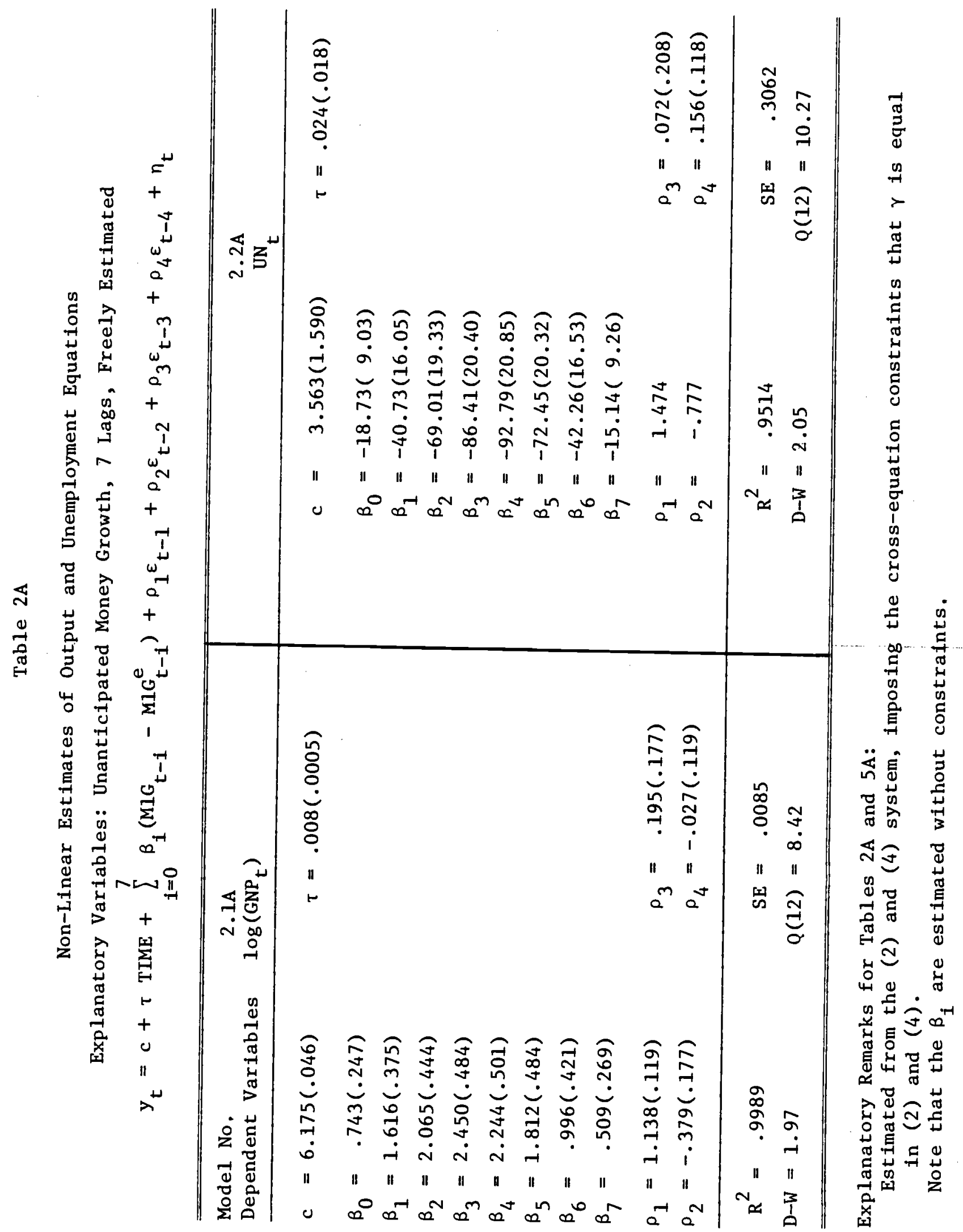


Table 3A

Likelihood Ratio Tests for the Models of Table 2A

\begin{tabular}{lcc}
\hline \hline Model No. & $2.1 \mathrm{~A}$ & $2.2 \mathrm{~A}$ \\
\hline Joint Hypothesis & & \\
Likelihood Ratio Statistic & $\chi^{2}(20)=22.37$ & $\chi^{2}(20)=31.55$ \\
Marginal Significance Level & .3210 & .0484 \\
Neutrality & $\chi^{2}(8)=9.53$ & .1524 \\
Likelihood Ratio Statistic & .2996 & $\chi^{2}(8)=11.97$ \\
Marginal Significance Level & & $\chi^{2}(12)=20.14$ \\
Rationality & $\chi^{2}(12)=12.34$ & .0645 \\
Likelihood Ratio Statistic & .4187 & \\
Marginal Significance Level & & \\
\hline \hline
\end{tabular}




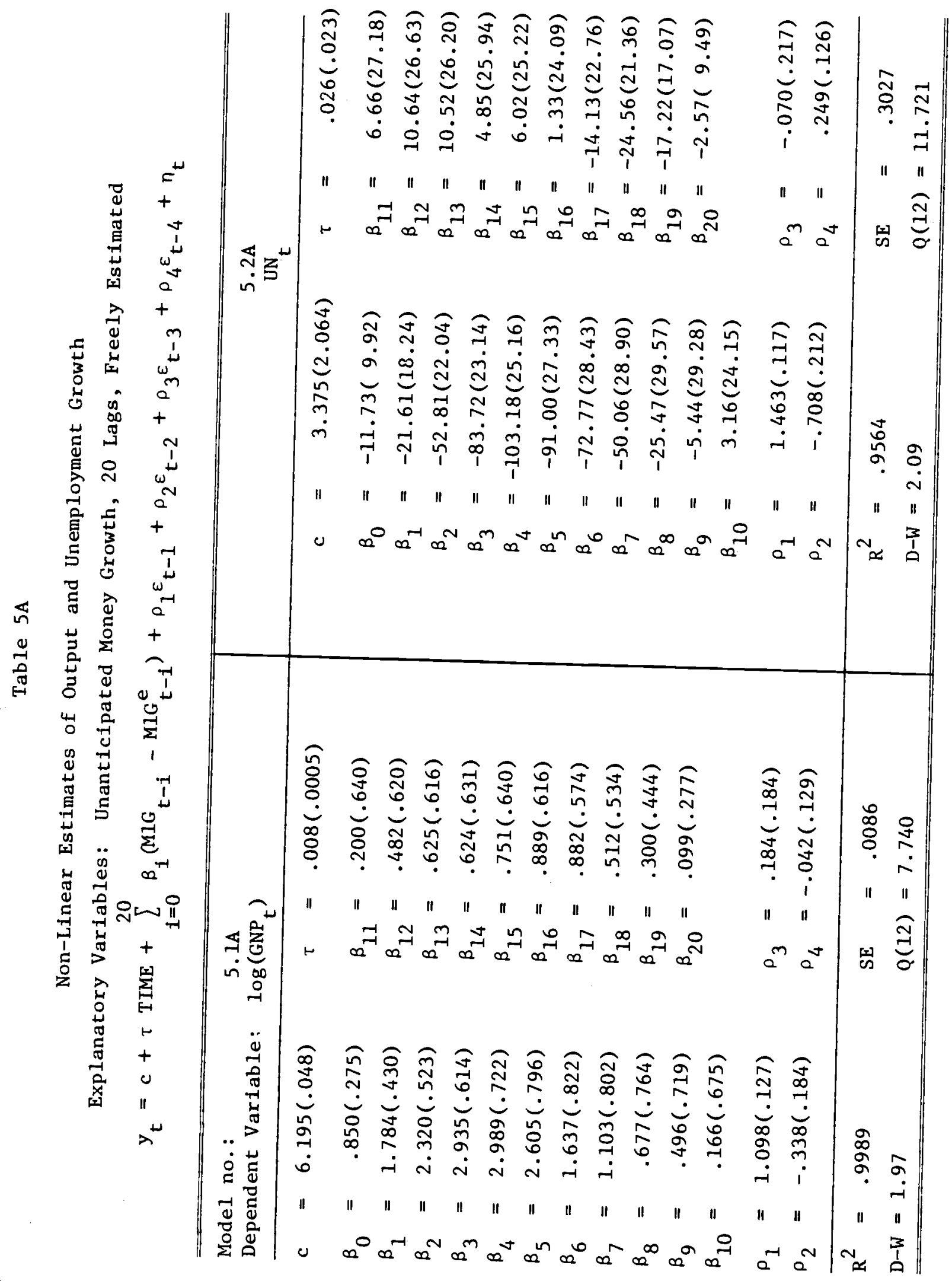


Table 6A

Likelihood Ratio Tests for the Models of Table 5A

\begin{tabular}{lcc}
\hline Model No. & $5.1 \mathrm{~A}$ & $5.2 \mathrm{~A}$ \\
\hline $\begin{array}{l}\text { Joint Hypothesis } \\
\text { Likelihood Ratio Statistic } \\
\text { Marginal Significance Level }\end{array}$ & $\chi^{2}(33)=66.90$ & $\chi^{2}(33)=54.06$ \\
Neutrality & .0004 & .0118 \\
$\begin{array}{l}\text { Likelihood Ratio Statistic } \\
\text { Marginal Significance Level }\end{array}$ & $\chi^{2}(21)=45.22$ & $\chi^{2}(21)=30.47$ \\
Rationality & .0016 & .0830 \\
Likelihood Ratio Statistic & $\chi^{2}(12)=27.10$ & $\chi^{2}(12)=27.01$ \\
Marginal Significance Level & .0075 & .0077 \\
\hline \hline
\end{tabular}


REFERENCES

Abel, A. and Mishkin, F. S. "On the Econometric Testing of Rationality and Market Efficiency." Report 7933, Center for Mathematical Studies in Business and Economics, University of Chicago, August 1979.

Barro, R. J. "Unanticipated Money Growth and Unemployment in the United States." American Economic Review 67, No.2 (March 1977): 101-115. - "Unanticipated Money, Output, and the Price Level in the United States." Journal of Political Economy 86 (August 1978): 549-580. - "Unanticlpated Money Growth and Unemployment in the United states: Reply." American Economic Review, 69 (December 1979): 1004-1009.

Barro, R. J. and Rush, M. "Unanticipated Money and Economic Activity Results from Annual and quarterly U.S. Data." Unpublished paper, University of Rochester, September 1978.

Box, G. E. P., and Pierce, D.A. "Distribution of Residual Autocorrelation In Autoregressive-Integrated Moving Average Time Series Models." Journal of the American Statistical Assoclation 65 (December 1970) 1509-1526.

Chow, G.C. "Tests of Equality Between Sets of Coefficients in Two Linear Regressions." Econometricia 28 (1960): 591-605.

Durbin, J. "Testing for Serial Correlation in Least Squares Regression when some of the Regressors are Lagged Dependent Variables." Econometrica 38 (May 1970): 410-421.

Fair, R. "The Sensitivity of Fiscal-Policy Effects to Assumptions about the Behavior of the Federal Reserve." Econometrica 46 (1978) 
Fiege, E. L. and Pearce, D. K. "Economically Rational Expectations: Are Innovations in the Rate of Inflation Independent of Innovations in Measures of Monetary and Fiscal Policy?" Journal of Political Economy, 84 (June 1976): 499-522.

Fischer, S. "Long Term Contracts, Rational Expectations, and the Optimal Money Supply Rule." Journal of Political Economy 85 (February 1977): 191-206.

Friedman, M. "The Demand for Money- - Some Theoretical and Empirical Results." Journal of Political Econorgy 67 (June 1959): 327 - 351. - "The Role of Monetary Policy." American Economic Review 58 (March 1968): 1-17.

Germany, J. D. and Srivastava, S. "Empirical Estimates of Unanticipated Policy: Issues In Stability and Identification." Unpublished paper, MIT, December 1979.

Goldfeld, S. M. and Quandt, R. E. "Some Tests for Homoscedasticity." Journal of the American Statistical Association 60 (1965): 539-547. - Non-linear Methods in Econometrics. Amsterdam: North Holland, 1972.

Gordon, R. J. 'New Evidence that Fully Anticipated Monetary Changes Influence Real Output After A11." Discussion Paper No. 369, The Center for Mathematical Studies in Economics and Management Science, Northwestern University, March 1979.

Granger, C. W. J. "Investigating Causal Relations by Econometric Models and Cross-spectral Methods." Econometrica 37 (July 1969): 424-438.

Granger, C. W. J. and Newbold, P. "Spurious Regressions in Econometrics." Journal of Econometrics 2 (1974): 111-120. 
Laidler, D. The Demand for Money: Theories and Evidence. Dunn-Donelly, 1977 :

Leiderman, L. "Macroeconometric Testing of the Rational Expectations and Structural Neutrality Hypothesis for the United States." Boston University, August 1978, forthcoming in the Journal of Monetary Economics.

Lucas, R. E. Jr, "Expectations and the Neutrality of Money." Journal of Economic Theory 4 (April 1272); 103-124.

Mishkin, F. S. "Efficient-Markets Theory: Implications for Monetary Policy." Brookings Papers on Economic Activity 3 (1978): 707-752. - "Monetary Policy and Long-term Interest Rates: An Efficient Markets Approach." Unpublished paper, University of Chicago, January 1980. Forthcoming in the Journal of Monetary Economics. (a) - "Are Market Forecasts Rational?" Unpublished paper, University of Chicago, March 1980.

"Does Anticipated Aggregate Demand Policy Matter? An Econometric Investigation." University of Chicago, February 1980. (c)

Modigliani, F. "The Monetarist Controversy or, Should We Forsake Stabilization Policies?" American Economic Review 67 (March 1977) : 1-19.

Muth, J. F. "Rational Expectations and the Theory of Price Movements." Econometrica 29 (July 1961): 315-335.

Phelps, E. S. "Phillips Curves, Expectations of Inflation, and Optimal Unemployment Over Time." Economica 34 (August 1967): 254-281.

Phelps, E. S. and Taylor, J. B. "Stabilizing Powers of Monetary Policy Under Rational Expectations. Journal of Polltical Economy 85 (February 1977): 163-190.

Plosser, C. I. and Schwert, G. W. "Money, Income, and Sunspots: Measuring Economic Relationships and the Effects of Differencing." Journal of Monetary Economics 4 (November 1978): 637-660. 
Sargent, T. J. "A Classical Macroeconomic Model for the United States." Journal of Political Economy 84 (April 1976): 207-237.

Sargent, T. J. and Wallace, N. "Rational Expectations, the Optimal Monetary Instmument and the Optimal Money Supply Rule." Journal of Political Economy 83 (October 1975): 241-254.

Shiller, R. J. "The Volatility of Long-term Interest Rates and Expectations Models of the Term Structure." Journal of Political Economy 87 , (December 1979): 1190-1219.

Sims, C. A. "Comment." Journal of the American Statistical Association $72($ March 1977): 23-24.

Small, D. H. "Unanticipated Money Growth and Unemployment in the Unites States Comment." American Economic Review 69 (December 1979): 996-1003.

Taylor, J. B. "Estimation and Control of a Macroeconomic Model with Rational Expectations" Econometrica forthcoming.

Wallace, N. "Microeconomic Theories of Macroeconomic Phenomena and their Implications for Monetary Policy." In A Prescription for Monetary Policy: Proceedings from a Seminar Series. Federal Reserve Bank of Minneapolis, 1976.

Zellner, A. "Causality and Econometrics." In Three Aspects of Policy and Policymaking: Knowledge, Data and Institutions. Edited by K. Brunner and A. H. Meltzer. Carnegie-Rochester Conference Serives V. 10. Amsterdam: North Holland, 1979. Pp. 9-54. 